\title{
Porencephaly presenting with anger outbursts: A case report
}

\author{
Rakesh K Singh ${ }^{1}$, Suprakash Chaudhury ${ }^{2, *}$, Chetan Diwan ${ }^{3}$, Spandana Devabhaktuni ${ }^{4}$
}

${ }^{1,2}$ Professor, ${ }^{3}$ Assistant Professor, ${ }^{4}$ Senior Resident, ${ }^{1,2,4}$ Dept. of Psychiatry, ${ }^{3}$ Dept. of Social Work, ${ }^{1}$ Hind Institute of Medical Science, Lucknow, Uttar Pradesh, ${ }^{2,4}$ Dr. D Y Patil Medical College, Hospital \& Research Center, Pimpri, Pune, Maharashtra, ${ }^{3}$ Karve Institute of Social Service, Pune, Maharashtra, India

*Corresponding Author:

Email: suprakashch@gmail.com

\begin{abstract}
Porencephaly is an extremely rare congenital disorder characterized by a cyst or a cavity filled with cerebrospinal fluid, in the brain's parenchyma. An 18-year-old male with moderate intellectual disability presented with periodic unprovoked anger outbursts lasting 3-5 minutes of recent onset. Computed tomography of the head was done after the consultation and revealed a large porencephalic cyst in the left frontotemporal region. The patient responded well with tablet Clobazam 5mg BD and tablet Sodium Valproate 300mg BD. The condition is briefly discussed.
\end{abstract}

Keywords: Porencephaly, Seizures, Psychosis.

\section{Introduction}

Porencephaly is an extremely rare disorder of the central nervous system characterized by a single or multiple cysts or cavities filled with cerebrospinal fluid, in the brain's parenchyma. ${ }^{1}$ These cysts can be located in any lobe or lobes of the two cerebral hemispheres. ${ }^{2}$ Porencephaly is classified into two groups: congenital porencephaly and acquired porencephaly. ${ }^{2}$ Causes of acquired porencephaly include cerebral infarction, trauma, hemorrhage, infection of the brain parenchyma, and idiopathic causes. ${ }^{2}$ Congenital porencephaly includes two types: Genetic porencephaly that occurs due to mal-development during early neuronal migration and encephalophaloplastic porencephaly, which is a late prenatal or perinatal vascular lesion due to arterial ischemic stroke or venous thrombosis. ${ }^{3}$ Depending on the patient, this disorder may cause only minor neurological problems without any disruption on intelligence, while others may be severely disabled or die before 20 years of age. While the exact prevalence of porencephaly is yet to be determined, studies have reported a prevalence of $6.8 \%$ in patients with cerebral palsy and $68 \%$ in patients with epilepsy and congenital vascular hemiparesis. ${ }^{4}$ We report a case of Porencephaly presenting with anger outbursts due to its rarity.

\section{Case History}

An eighteen-year-old male student belonging to middle socio-economic status was brought to the outpatient department with periodic unprovoked anger outbursts. His mother gave the history of two to three such episodes per day lasting for three to five minutes each. Mother reports that until a couple of months back her son seldom lost his temper and was not prone to such aggressive display of temper. During these episodes, the patient would suddenly verbally abuse and throw the things around him. He had no past psychiatric history or family psychiatric history. Natal history reveals delayed birth cry with delayed milestones of development with moderate intellectual disability.
A neurological examination was conducted and the results of his motor, sensory, and cerebellar examinations were normal. The Babinski sign was negative. Laboratory investigations including hemogram, urine routine examination, blood sugar, liver function tests were within normal limits. Electroencephalogram studies show background beta waves with no spikes or sharp waves. Computed tomography of the head revealed a large porencephalic cyst in the left frontotemporal region (Fig. 1). The patient responded well with tablet Clobazam 5mg BD and tablet Sodium Valproate $300 \mathrm{mg}$ BD bid with decreased frequency of episodes of dyscontrol.

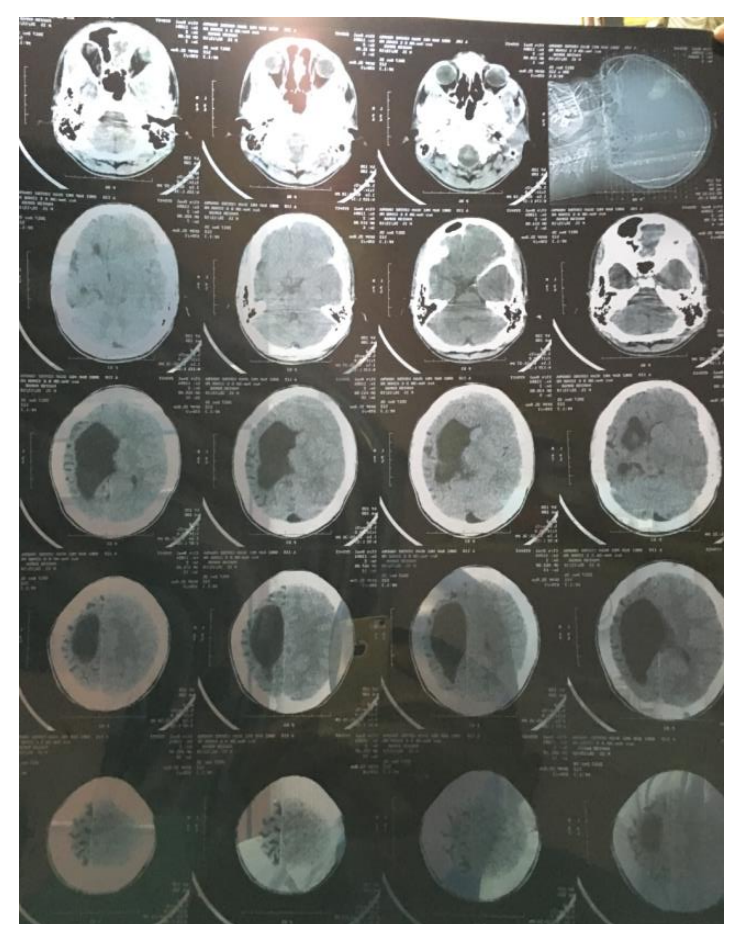

Fig. 1: Computed tomography of head showing a large porencephalic cyst in the left frontotemporal region 


\section{Discussion}

Heschl in 1859 first used the term porencephaly to describe cavities in the cerebral hemispheres which he attributed to destruction of the fetal brain. ${ }^{5}$ Since then, the term "porencephaly" has been used to describe etiologically different brain cavities communicating with either the lateral ventricles or the subarachnoid space. COL4A1 has been proved to be a major locus for genetic predisposition to perinatal cerebral haemorrhage and porencephaly. ${ }^{6}$ The diagnosis of a COL4A1-related disorder is established in a patient with suggestive features and the identification of a heterozygous pathogenic variant in COL4A1. Once the COL4A1 pathogenic variant has been identified in an affected family member, prenatal testing and preimplantation genetic diagnosis for pregnancy at increased risk for a COL4A1-related disorder may be done. ${ }^{7}$ Porencephaly usually results from stroke or infection more commonly, but it may also be caused due to abnormal development before birth. These injuries lead to the destruction of brain tissue and cavitations which may manifest as multicystic encephalomalacia or porencephaly. Insults occurring at the end of the second or the beginning of the third trimester of pregnancy manifest as porencephaly as they affect an immature brain unable to express significant astrocyte reaction. ${ }^{8-9}$ Infants may have poor or absent speech development, epilepsy, hydrocephalus, spastic contracture, and cognitive impairment. Psychosis has also been reported. ${ }^{10-11}$ At present no specific treatment is available. The various treatment options used are removing the cysts surgically, antiepileptics, placing a shunt, rehabilitation and physical therapies. Lifelong treatment and monitoring are necessary for the most severe cases. The prognosis of porencephaly depends on the location and extent of the cyst. In some patients, it presents as minor neurological problems without affecting intelligence. It may also present with serious life-threatening disabilities leading to death even before the second decade.

\section{Conflict of Interest: None.}

\section{References}

1. Stevenson RE, Hall JG: Porencephaly. Human malformations and related anomalies. Oxford: Oxford University Press, 2006. Pp. 645-654.

2. Tonni G, Ferrari B, Defelice C, Gentini G. Neonatal porencephaly in very low birth weight infants: Ultrasound timing of asphyxial injury and neurodevelopmental outcome at two years of age. J Matern-Fetal Neonatal Med 2005;18(6):361-365.

3. Douzenis A, Rizos EN, Papadopoulou A, Papathanasiou M, Lykouras L. Porencephaly and psychosis: a case report and review of the literature. BMC Psychiatry 2010; 10:19. http://www.biomedcentral.com/1471-244X/10/19

4. Inah GB. Left cerebellar porencephalic cysts with ipsilateral parieto-occipital encephalocoele: Antenal and post natal radiology. IOSR J Dent Med Sci 2018;17(8):82-87.

5. Heschl R. Gehirndefect und hydrocephalus. Prag Vjschr Prakt Heilk 1859;61:59-74

6. Breedveld G, De Coo IF, Lequin MH, Arts WF, Heutink P, Gould DB, et al. Novel mutations in three families confirm a major role of COL4A1 in hereditary porencephaly. J Med Genet 2006;43(6):490-495.

7. Gould DB, Phalan FC, van Mil SE, Sundberg JP, Vahedi K, Massin P, et al. Role of COL4A1 in small-vessel disease and hemorrhagic stroke. New Engl J Med 2006;354(14):14891496.

8. Erasmus C, Blackwood W, Wilson J. Infantile multicystic encephalomalacia after maternal bee sting anaphylaxis during pregnancy. Arch Dis Child 1982;57(10):785-787.

9. Wiklund LM, Uvebrant P, Flodmark O. Morphology of cerebral lesions in children with congenital hemiplegia. Neuroradiol 1990;32(3):179-186.

10. Eller KM, Kuller JA. Fetal porencephaly: a review of etiology, diagnosis, and prognosis. Obstetrical and Gynecological survey. 1995;50(9):684-687.

11. O. C. Noyan, C. Şalçini, B. S. Talu, G. Eryilmaz. Porencephalic cyst and late onset brief psychotic disorder. BMJ Case Rep 2016. DOI: 10.1126/science.1109418. 